Illinois State University

ISU ReD: Research and eData

Theses and Dissertations

$12-6-2019$

\title{
A Male-Female Genotype-By-Genotype Interaction Mediates The Effect Of Mating On Female Immunity In Decorated Crickets
}

Kylie J. Hampton

Illinois State University, kyliejeanhampton@gmail.com

Follow this and additional works at: https://ir.library.illinoisstate.edu/etd

Part of the Biology Commons, and the Ecology and Evolutionary Biology Commons

\section{Recommended Citation}

Hampton, Kylie J., "A Male-Female Genotype-By-Genotype Interaction Mediates The Effect Of Mating On Female Immunity In Decorated Crickets" (2019). Theses and Dissertations. 1193.

https://ir.library.illinoisstate.edu/etd/1193

This Thesis is brought to you for free and open access by ISU ReD: Research and eData. It has been accepted for inclusion in Theses and Dissertations by an authorized administrator of ISU ReD: Research and eData. For more information, please contact ISUReD@ilstu.edu. 


\section{A MALE-FEMALE GENOTYPE-BY-GENOTYPE INTERACTION MEDIATES THE EFFECT OF MATING ON FEMALE IMMUNITY IN DECORATED CRICKETS}

\section{KYLIE J. HAMPTON}

\section{Pages}

Sexually antagonistic coevolution should lead to the rapid divergence of male and female genotypes related to the effects of ejaculatory substances on female physiology. Hence, the outcome of mating should depend on an interaction between male and female genotypes. Although mating has been shown to influence female immune responses in diverse insect taxa, a male-female genotype-by-genotype effect on female immunity post-mating remains largely unexplored. Here, we investigate both the effects of mating on female immunity and the potential for a male-by-female genotype interaction on the form and magnitude of this response in decorated crickets. Females from three distinct genotypic backgrounds were either left unmated or singly mated in a fully reciprocal design to males from the same three genotypic backgrounds. Female cellular immunity was assayed by quantifying circulating hemocytes and the presence of hemocyte microaggregations. Humoral immunity was assessed by measuring total phenoloxidase activity, an enzyme involved in melanization, and general antibacterial activity. Mated females exhibited a higher incidence of microaggregations than virgin females, indicative of a general response to mating. We also found evidence for a male-female genotype-by-genotype interaction on cellular immune measures. Specifically, the number of circulating hemocytes in mated females was contingent on an interaction between her genotype and that of her mate, and a trend of similar interaction emerged in the incidence of microaggregations. These results suggest that 
the ejaculates of males of different lines have diverged with respect to their effect on female immunity, and similarly, that females differ in their susceptibility to these compounds. KEYWORDS: cellular immunity, crickets, genotype-by-genotype interaction, humoral immunity, mating, seminal proteins, sexually antagonistic coevolution 
A MALE-FEMALE GENOTYPE-BY-GENOTYPE INTERACTION MEDIATES THE EFFECT OF MATING ON FEMALE IMMUNITY IN DECORATED CRICKETS

KYLIE J. HAMPTON

\author{
A Thesis Submitted in Partial \\ Fulfillment of the Requirements \\ for the Degree of \\ MASTER OF SCIENCE \\ School of Biological Sciences \\ ILLINOIS STATE UNIVERSITY
}


Copyright 2020 Kylie J. Hampton 
A MALE-FEMALE GENOTYPE-BY-GENOTYPE INTERACTION MEDIATES THE EFFECT OF MATING ON FEMALE IMMUNITY IN DECORATED CRICKETS

KYLIE J. HAMPTON

COMMITTEE MEMBERS:

Benjamin M. Sadd, Co-Chair

Scott K. Sakaluk, Co-Chair

Steven A. Juliano

Laura A. Vogel 


\section{ACKNOWLEDGMENTS}

This research was funded by a grant from the National Science Foundation to S.K.S., B.M.S., and J.H. (IOS 16-54028), a grant from the Australian Research Council to J.H. (DP180101708), grants from the Beta Lambda Chapter of the Phi Sigma Biological Honor Society and the Animal Behaviour Student Research Grant to K.J.H, and an E.L. Mockford and C.F. Thompson Summer Research Fellowship to K.J.H. During the preparation of this manuscript, S.K.S. was supported by a scholarship from the Deutscher Akademischer Austauschdienst under the auspices of the Research Stays for University Academics and Scientists program.

K.J.H. 


\section{CONTENTS}

Page

ACKNOWLEDGMENTS

CHAPTER I: INTRODUCTION AND METHODS 1

Introduction $\quad 1$

Methods

Study Animals $\quad 5$

$\begin{array}{ll}\text { Mating Observations } & 6\end{array}$

$\begin{array}{ll}\text { Quantifying Immune Function } & 7\end{array}$

$\begin{array}{ll}\text { Antibacterial Activity Assay } & 8\end{array}$

$\begin{array}{ll}\text { Total Phenoloxidase Activity Assay } & 10\end{array}$

$\begin{array}{ll}\text { Circulating Hemocyte Counts and Microaggregations } & 11\end{array}$

$\begin{array}{ll}\text { Statistical Analysis } & 11\end{array}$

CHAPTER II: RESULTS AND DISCUSSION 13

$\begin{array}{ll}\text { Results } & 13\end{array}$

$\begin{array}{ll}\text { Mating Behavior } & 13\end{array}$

$\begin{array}{ll}\text { Antibacterial Activity } & 13\end{array}$

Total Phenoloxidase Activity 14

$\begin{array}{ll}\text { Circulating Hemocytes } & 14\end{array}$

Proportions of Individuals with Microaggregations 15

$\begin{array}{ll}\text { Discussion } & 15\end{array}$

$\begin{array}{ll}\text { REFERENCES } & 22\end{array}$

APPENDIX A: TABLES AND FIGURES 33 


\section{CHAPTER I: INTRODUCTION AND METHODS}

\section{Introduction}

Sexual conflict ensues when individuals pursue reproductive strategies that are detrimental to the fitness of their mates (Chapman, Arnqvist, Bangham, \& Rowe, 2003a). Such conflicts can occur before, during, or after mating, and can manifest in various ways. An especially pervasive conflict arises over female remating rates in polyandrous species (Arnqvist \& Nilsson, 2000; Chapman, Arnqvist, Bangham, \& Rowe, 2003a; Rowe \& Arnqvist, 2002). Although females can increase their reproductive success by trading up in the quality of their mates, rematings with additional males invariably increases the likelihood of sperm competition, resulting in decreased paternity of females' respective mating partners (Parker \& Birkhead, 2013). In an attempt to mitigate these costs, males may evolve reproductive tactics that function to control female remating (Arnqvist \& Rowe, 2002; Dougherty et al., 2017). In various insect species, for example, males attempt to thwart female remating using various behavioral means, including prolonged copulation, passive-phase guarding in which males continue to physically grasp females after mating, and, more commonly, through mate guarding (Alcock, 1994; Arnqvist, 1988; Cordero, 1990, 1999; Sakaluk, 1991; Sherman, 1983).

In addition to controlling female remating rates using behavioral tactics, some males attempt to control female remating via their ejaculates. In several insect orders, a portion of the male's ejaculate serves as a mating plug that functions to prevent subsequent insemination by other males (Baer, Morgan, \& Schmid-Hempel, 2001; Dickinson \& Rutowski, 1989; Lung \& Wolfner, 2001). More broadly, the seminal fluids of various male insects contain seminal fluid proteins (accessory gland proteins) that may also influence female remating through their effects on female physiology and behavior (Gillott, 2003; Klowden, 1999; Sakaluk, Avery, \& Weddle, 
2006). In Drosophila melanogaster, for example, seminal proteins have been identified that reduce female receptivity to further courtship attempts by other males (Wigby \& Chapman, 2005; Wolfner, 1997). Insect seminal fluid proteins are also known to manipulate other facets of female reproduction post-mating (reviewed in Avila et al., 2010). Work in Drosophila has elegantly connected certain seminal proteins with mating-induced changes in female egg production and ovulation, as well as changes in female immunity (reviewed in Ravi Ram \& Wolfner, 2007). Sex peptide is a widely investigated seminal fluid protein in Drosophila that is known to carry out several functions, including the upregulation of antimicrobial peptides in mated females. Peng, Zipperlen, and Kubli (2005) demonstrated that the expression of the antimicrobial peptides, metchnikowin, drosomycin, and diptericin are stimulated shortly after mating in female Drosophila. Alteration of female immunity post-mating through physiological effects of male ejaculatory substances is one of multiple ways that mating can influence female immunity (Lawniczak et al., 2007). The corruption or enhancement of female immunity by mating and its subsequent influence on infection outcomes will affect the evolutionary landscape of sexual conflict. Although widely debated (Short \& Lazzaro, 2010), one expectation is that sexually antagonistic coevolution should lead to the rapid divergence of male and female genotypes related to the effects of seminal proteins on female physiology (Goenaga, Yamane, Rönn, \& Arnqvist, 2015; Haerty et al., 2007; Rice \& Holland, 1997). As a consequence of sexually antagonistic coevolution, males from different populations and genotypes should differ in the manipulative effect of transferred substances, and similarly, females should differ in their susceptibility to these compounds. Genotypic differences necessitate, therefore, that the outcome of mating should depend on a genotype-by-genotype interaction. Indeed, a recent study has demonstrated that the expression of female Drosophila immune genes post-mating depends on 
the interaction between male and female genotype (Delbare, Chow, Wolfner, \& Clark, 2017). However, this genotype-by-genotype interaction has not been explicitly investigated in relation to functional impacts on female immunity.

The decorated cricket (Gryllodes sigillatus) has become a focal study organism for investigating sexual conflict over female mating behavior (Sakaluk et al., 2019), primarily because of the nuptial food gifts offered by males to females at mating that are known to influence female physiology and behavior (Sakaluk, 2000; Sakaluk, Avery, \& Weddle, 2006; Warwick, Vahed, Raubenheimer, \& Simpson, 2009). The spermatophore transferred by a male during copulation comprises a small sperm-containing ampulla enveloped by a gelatinous spermatophylax that the female detaches from the ampulla and consumes immediately after mating as a form of nuptial feeding. Once the female has finished consuming the spermatophylax, she also detaches and eats the sperm ampulla, terminating sperm transfer (Sakaluk, 1984; Sakaluk, 1987). Free amino acids contained within the spermatophylax function to enhance its gustatory appeal, extending the time the female spends feeding on it before she discards it (Gershman, Mitchell, Sakaluk, \& Hunt, 2012; Gershman, Hunt, \& Sakaluk, 2013; Warwick, Vahed, Raubenheimer, \& Simpson, 2009), thereby promoting greater sperm transfer and enhancing male fertilization success (Sakaluk, 1986; Sakaluk \& Eggert, 1996; Eggert, Reinhardt, \& Sakaluk, 2003). Additionally, the food gifts of male G. sigillatus contain proteins that may serve to manipulate female sexual receptivity (Sakaluk, Avery, \& Weddle, 2006). Indeed, recent proteomic analysis has identified a number of proteins in the spermatophylax with the potential to manipulate components of female reproductive physiology (Pauchet et al., 2015). Previous studies have revealed that mating can also influence immunity in decorated crickets, specifically with respect to trade-offs between reproductive effort and immunity in males 
(Gershman et al., 2010b; Kerr, Gershman, \& Sakaluk, 2010). For example, Gershman et al. (2010b) identified a phenotypic trade-off between lytic activity, an important facet of antibacterial immunity, and the mass of the spermatophylax synthesized by the male. Kerr, Gershman, and Sakaluk (2010) demonstrated a reciprocal trade-off between immunity and reproduction in G. sigillatus, in which immune challenged males produced smaller spermatophores, whereas experimentally-induced spermatophore production in males resulted in decreased immune function. More recently, Duffield et al. (2018) showed that the total number of circulating hemocytes of male crickets increases following a bacterially-based immune challenge. A previous study identified differences in immunity among males and females of different G. sigillatus inbred lines (Gershman et al., 2010a). However, the effects of mating on female immunity in G. sigillatus are still largely unknown.

Here, we investigate how mating per se affects female immunity in decorated crickets, and also whether male genotype interacts with female genotype to influence female immunity post-mating. To assess the effects of mating on female immunity, we compared female cellular and humoral immunity between mated and virgin females. To determine whether male genotype interacts with female genotype in mediating differences in female immunity post-mating, we assigned females of known genotype to mate with males from the same genotypic background or a different genotypic background, after which female cellular and humoral immunity were assessed. Based on previous studies investigating the effects of mating on immunity in insects (Lawniczak et al. 2007; Schwenke, Lazzaro, \& Wolfner, 2016), we predicted that mated females would differ from virgin females in one or more parameters of immunity. Among mated females, we predicted that the immune profiles of females mated to males from the same genotype would 
differ from females mated to males from different genotypes, due to an established history of sexually antagonistic coevolution among them.

\section{Methods}

\section{Study Animals}

G. sigillatus used in this study were randomly selected from three genetically distinct inbred lines (designated E, F, and I) that were established in 2001 from a wild-caught population of approximately 500 individuals collected in Las Cruces, New Mexico. Inbred lines were created by subjecting crickets to 23 generations of full-sib mating, followed by panmixia within lines thereafter (Ivy, Weddle, \& Sakaluk, 2005). Previous work has revealed that these inbred lines vary in a number of phenotypic and life history traits, including differences in lifespan, female fecundity, male calling effort, nuptial gift composition, and immune function (Archer et al., 2012; Duffield et al., 2019; Gershman et al., 2010a,b; Gershman, Hunt, \& Sakaluk, 2013). Lines used in this study were at similar stages of development at the beginning of the experiment.

All crickets were maintained under standard rearing conditions. Individuals were housed in 19L ventilated, plastic storage bins lined with egg carton to increase rearing surface area and provided with cat chow (Purina Cat Chow Complete ${ }^{\mathrm{TM}}$ ), rodent meal $\left(\right.$ Envigo $^{\odot} 2018 \mathrm{CM}$ Teklad Certified Global 18\% protein rodent diet), and water (in glass vials plugged with cotton) ad libitum. To ensure their virginity, juvenile males and females were separated when sex differences became apparent $\left(4^{\text {th }}\right.$ or $5^{\text {th }}$ instar). Females were individually housed in clear $0.47 \mathrm{~L}$ PET plastic deli containers whereas males were housed in groups of roughly 10 males per line in 5.68L ventilated, plastic boxes. All individuals were housed in an environmental chamber at 
$32^{\circ} \mathrm{C}$ on a $14 \mathrm{hr}: 10 \mathrm{hr}$ light:dark cycle. Juvenile males and females were checked twice weekly for eclosion. At the time of mating, all experimental females were 7-9 days-old adults and males were 4-12 days-old adults. Female G. sigillatus become sexually mature 2-4 days post-eclosion and male G. sigillatus 4-11 days post-eclosion (Burpee \& Sakaluk, 1993; Sakaluk, 1987).

\section{Mating Observations}

Sexually mature females were randomly assigned to a mating status treatment: mated (singly) or virgin. Genotype-by-genotype treatments were nested within the mated treatment, with females randomly paired with a male from their same line or from one of the other two inbred lines, creating a fully reciprocal design of all possible male and female genotype combinations (Figure 1). To confirm mating success, crickets were viewed in clear plastic viewing chambers $(10.5 \mathrm{~cm}$ X $7.5 \mathrm{~cm} \mathrm{X} 3 \mathrm{~cm})$ lined with paper towels under red light (Ivy \& Sakaluk, 2005). All mating trials took place at similar time points during the dark period of their light cycle to capture a time most relevant to their mating behavior in nature (Sakaluk, 1987; Sakaluk et al., 2002). For each mating pair, courtship and copulation behaviors were recorded from the time the male was introduced into the viewing chamber. These included: time to courtship (i.e., comprising both song and distinctive vibratory movements by the male to entice the female to mount), time to female mounting (i.e., a female's decision to accept a mate), time to mating (i.e., successful transfer of the spermatophore from the male to the female), time to gift consumption (i.e., when the female removed the spermatophylax from the spermatophore), time to termination of gift consumption (i.e., when the female finished eating the gift, either fully consuming it or prematurely discarding it), and time to removal of the sperm ampulla (i.e., when the female terminates sperm transfer by removing the sperm ampulla). Because courtship is 
essential for mating to occur in crickets (Sakaluk, 1987), if a male did not initiate courtship within the first 10 minutes of being introduced into the mating chamber, he was removed from the chamber and replaced with a different male from the same line. Females, on average, were provided with 2.4 different males over the course of two days until mating took place. If a female did not mate within two days, she was removed from the experiment. For females that did mate but did not prematurely remove the sperm ampulla, sperm transfer was standardized by manually removing the sperm ampulla after $50 \mathrm{~min}$, which is enough time to ensure complete sperm transfer (Sakaluk, 1984). For all mated females, the total number of males she was provided, her age, and the age of her mate was recorded. To control for any potential differences due to the exposure to a male conspecific per se (Zhong et al., 2013), females assigned to the virgin mating status treatment were placed with a juvenile male for 60 minutes.

\section{Quantifying Immune Function}

Immunity of mated females was assessed 24 hours after mating or juvenile male exposure for virgin females. This time frame is similar to other studies in insects that have demonstrated mating effects on female immunity (Barribeau \& Schmid-Hempel, 2017; Fedorka, Zuk, \& Mousseau, 2004; Peng, Zipperlen, \& Kubli, 2005; Rolff \& Siva-Jothy, 2002). To quantify immune function, three immune assays that encompass both cellular and humoral aspects of the insect immune response (Gillespie, Kanost, \& Trenczek, 1997) were employed. Specifically, we measured i) counts of the total number of circulating hemocytes and presence of hemocyte microaggregations representing cellular immunity, and ii) enzymatic activity of total phenoloxidase (PO) and iii) cell-free antibacterial activity representing humoral immunity. Because insect immunity is multifaceted, measuring both cellular and humoral immunity 
captures a suite of potential female immune responses to mating (Gillespie, Kanost, \& Trenczek, 1997; Shoemaker, Parsons, \& Adamo, 2006).

Hemolymph was extracted from cold-anesthetized females by piercing the membrane above the dorsal pronotum plate with a sterile $25-\mathrm{G}$ needle. Four microliters of outflowing hemolymph were collected with a chilled microcapillary tube at the puncture site. Collected hemolymph was expelled into $11 \mu 1$ of chilled Grace's Insect Medium (MilliporeSigma, CAS: G8142) to be used directly for the antibacterial activity assay. Four microliters of this solution were subsequently taken and added to $20 \mu \mathrm{l}$ of Grace's Insect Medium for assaying the enzymatic activity of total PO and an additional $4 \mu 1$ of this mixture was added to $15 \mu 1$ of Grace's Insect Medium to be used for quantifying circulating hemocytes and the presence of microaggregations. Circulating hemocytes and microaggregations were immediately counted following hemolymph collection, whereas samples for antibacterial activity and total PO activity were snap-frozen in liquid nitrogen and stored at $-80^{\circ} \mathrm{C}$ for later analysis.

\section{Antibacterial Activity Assay}

Antibacterial activity of cell-free hemolymph is an important component of the humoral immune response of insects. This antibacterial activity includes the action of both lysozyme-like enzymes and antimicrobial peptides (AMPs). Some highly conserved AMPs, such as defensin (Yi, Chowdhury, Huang, \& Yu, 2014), exhibit a broad range of antibacterial activity, targeting both gram-positive and gram-negative bacteria (Gillespie, Kanost, \& Trenczek, 1997). Insect lysozymes also defend against gram-positive bacteria through the catalyzation and destruction of bacterial cell walls (Schneider, 1985). 
A zone of inhibition assay following established protocols (Duffield et al., 2018) was used to assay the humoral antibacterial activity of all experimental females. Hemolymph samples were added to petri dishes containing agar seeded with the Gram-positive Micrococcus luteus (ATCC 4698). Micrococcus luteus used in petri dishes was taken from a single colony on a streak plate. Bacteria from the streak plate were then added to $7 \mathrm{~mL}$ of liquid media $(2 \mathrm{~g}$ peptone and $1.2 \mathrm{~g}$ meat extract in $400 \mathrm{~mL}$ of nanopure water, $\mathrm{pH} 6.99$ ) and allowed to incubate for 48 hours at $30^{\circ} \mathrm{C}$ to create a liquid culture. Following quantification of cell number, a fraction of this culture was added to liquid media containing $1 \%$ agar (i.e., seeded medium) held at $40^{\circ} \mathrm{C}$ to achieve a final density of $1.5 \times 10^{5}$ cells $/ \mathrm{mL}$. Six $\mathrm{mL}$ of seeded medium were poured evenly into a 100-mm diameter petri dish and was allowed to solidify. Sample wells were made in the solidified seeded medium using a Pasteur pipette (Volac D810). Hemolymph samples were thawed on ice and $2.5 \mu \mathrm{l}$ of samples were added to individual wells. Measurements of antibacterial activity were replicated by adding hemolymph samples from each female to two separate petri dishes. A negative control of Grace's Insect Medium was also included on each plate. After adding samples to wells, plates were inverted and incubated for $48 \mathrm{hrs}$ at $30^{\circ} \mathrm{C}$, after which the diameter of clear inhibition zones was measured from images taken of each sample. For each zone, two measurements of diameter were taken perpendicular to one another using ImageJ (Schneider, Rasband, \& Eliceiri, 2012) and then averaged. Measured zone diameters were converted to units of lysozyme, based on a standard curve of zone of inhibition measurements from lysozyme (from hen egg white, MilliporeSigma, CAS: 12650-88-3). For each individual, the average activity in lysozyme units was used in subsequent analyses. Zones were measured blind to treatment. 


\section{Total Phenoloxidase Activity Assay}

The phenoloxidase, or melanization, cascade is another important part of the humoral response of insects. At the onset of this cascade, a serine protease cleaves prophenoloxidase (proPO), the inactive zymogen form of PO that exists in the hemolymph, to create the active form of PO. After activation, PO catalyzes the production of melanin, as well as phenols, quinones and other cytotoxins (Nappi \& Vass, 1993; Sugumaran, Nellaiappan, \& Valivittan, 2000) to defend against multicellular pathogens and parasites, bacteria, fungi, and viruses (González-Santoyo \& Córdoba-Aguilar, 2012; Soderhall \& Cerenius, 1998; Sugumaran, Nellaiappan, \& Valivittan, 2000).

To measure total PO activity, $10 \mu 1$ of each diluted sample prepared for PO were added to an individual well of a 96-well microplate (CytoOne) containing $135 \mu \mathrm{l}$ of nanopore $\mathrm{H}_{2} 0,20 \mu \mathrm{l}$ of phosphate buffer solution ( $\mathrm{pH} 6.5$ ), and $5 \mu \mathrm{l}$ of chemotrypsin ( $5 \mathrm{mg} / \mathrm{ml}$; MilliporeSigma, CAS: C4129) and allowed to incubate at room temperature $\left(20^{\circ} \mathrm{C}\right)$ for 15 minutes. During this incubation period, chemotrypsin cleaves $\mathrm{PO}$ from proPO, simulating the natural activation step. After incubation, $20 \mu \mathrm{l}$ of L-DOPA (4 mg/ml; MilliporeSigma, CAS: D9628), the reactant in the melanization cascade that is converted to dopa-quinone by PO, was added to each well. Dopaquinone spontaneously converts to dopa-chrome causing a colormetric change that was measured by recording optical density (OD) of the solution with a spectrophotometer (Thermo Scientific Multiskan GO) at 490nm. OD readings were taken every 20 seconds for 60 minutes. The enzymatic activity is measured as the slope of the reaction curve (change in OD/time) during its linear phase. Samples were run in duplicate and averaged for each individual. 


\section{Circulating Hemocyte Counts and Microaggregations}

Hemocytes are specialized cells that are a key component of the cellular response of insect innate immunity, involved in core processes that include coagulation, phagocytosis, and encapsulation (Lavine \& Strand, 2002). Additionally, hemocytes are known to phagocytose microorganisms and subsequently form small aggregates (i.e., microaggregations) during the early stages of nodule formation in an attempt to clear large numbers of microbes from circulation (Gillespie, Kanost, \& Trenczek, 1997). Immediately after extraction, hemolymph was added to a counting chamber (Fast-Read® 102, Immune Systems Ltd., UK) and viewed at 400x magnification under a phase-contrast microscope. Hemocyte counts and the presence of microaggregations were recorded for each individual. Counting was performed blind to treatment.

\section{Statistical Analysis}

We used SAS statistical software (version 9.4; SAS Institute, Cary, NC, U.S.A.) for all analyses, and all tests were two-tailed $(\alpha=0.05)$. We used a Cox proportional-hazards regression model (survival analysis; PROC PHREG) to evaluate the effect of male genotype, female genotype, and their interaction on: 1) time to female mounting, 2) time spent feeding on the spermatophylax, and 3) time to removal of the sperm ampulla. The EXACT option was specified in the model statement to handle ties, instances in which different females had the same time for any of the aforementioned mating parameters, because this option assumes that mating events are continuous and ordered, assumptions that are likely met by our data. For the analysis of ampulla attachment time, we included spermatophylax consumption time as a covariate in the final model, as we know from previous studies that time spent feeding on the spermatophylax 
influences the timing of ampulla removal (Sakaluk, 1984). Females whose ampulla was removed 50 min after mating (i.e. after complete sperm transfer had occurred) were included as rightcensored observations. Any nonsignificant terms were removed from final models.

Variation in female immune measures was examined in two separate contexts to determine: 1) whether mating per se affects female immunity ("Mating Status model") and 2) whether male genotype interacts with female genotype post-mating to influence female immunity ("GxG model"). In the Mating Status model, we compared immune measures of virgin females and mated females within the same inbred lines, but in these analyses, only females that were mated to males of the same genotype were included to avoid confounding any effect of mating with an effect of male genotype. Hence, these analyses include two main effects, mating treatment (virgin versus mated) and female genotype (E, F, or I). In the GxG model, we included male genotype, female genotype, and the interaction between the two as main effects. Body size, measured as pronotum width, was initially included as a covariate in all immune responses, but was eliminated from the final models when it was found to be nonsignificant.

Humoral immune measures of hemolymph antibacterial and PO activity were assessed using general linear models (PROC GLM), whereas cellular immune measures (hemocyte counts and presence of microaggregations) were evaluated using generalized linear models. We used a generalized linear model with a negative binomial distribution and log link function (PROC GLIMMIX) for hemocyte counts, and a generalized linear mixed model (PROC GLIMMIX) with a binomial response and log link function for the presence (or absence) of microaggregations. In both the Mating Status and GxG models, lysozyme data were log transformed to meet the assumptions of normality (reported means and confidence intervals were back-transformed). 


\section{CHAPTER II: RESULTS AND DISCUSSION}

\section{Results}

\section{Mating Behavior}

There was no significant effect of male genotype (Wald $X^{2}{ }_{2,193}=1.11, p=0.57$ ), female genotype (Wald $X^{2}{ }_{2,193}=1.26, p=0.86$ ), or their interaction (Wald $X^{2}{ }_{4,193}=1.26, p=0.87$ ) on the female's propensity to mount a male. There was, however, a significant effect of female genotype on the time females spent feeding on the spermatophylax (Wald $X^{2}{ }_{2,183}=9.51, p=$ 0.0086), whereas neither male genotype (Wald $X^{2}{ }_{2,183}=1.26, p=0.53$ ) nor the interaction had a significant influence. Female genotype also significantly affected the time at which females removed the sperm ampulla (Wald $X^{2}{ }_{2,194}=7.9260, p=0.0190$ ), but neither male genotype (Wald $X_{2,194}^{2}=0.6797, p=0.7119$ ) nor the genotype-by-genotype interaction (Wald $X^{2}{ }_{4,194}=$ 2.8734, $p=0.5792$ ) were significant. When we included spermatophylax feeding time as a covariate in the analysis, the effect of female line disappeared and spermatophylax feeding time was the only factor accounting for the variation in ampulla attachment time (Wald $X^{2}{ }_{1,184}=$ 19.4159, $p=<.0001)$. Thus, although there are differences between lines in the timing of ampulla removal, these differences arise primarily because of differences between lines in how long females feed on the spermatophylax.

\section{Antibacterial Activity}

The effect of body size was retained in the final Mating Status model because it was found to explain a significant proportion of the variation in antibacterial activity, with larger females having higher activity (Table 1). However, we found no significant difference in antibacterial activity between virgin and mated females or among females of different genotypes 
(Table 1). In the GxG model, there was no significant effect of body size, female or male genotype, or the genotype-by-genotype interaction (Table 2).

\section{Total Phenoloxidase Activity}

In the Mating Status model, mated females did not significantly differ from virgin females in their total PO, nor did female genotype significantly influence total PO (Table 1). We also did not find an effect of a GxG interaction on total PO in the GxG model (Table 2). Total PO was found to be different across female genotypes among mated females (Table 2; Female Genotype: mean [lower, upper bounds of $95 \%$ confidence interval] = E: $0.727230[0.673514$, 0.780945], F: 0.661201 [0.608417, 0.713985], I: 0.631469 [0.579718, 0.683219]). Male genotype did not influence total PO (Table 2). Body size did not have an effect on total phenoloxidase activity in either model (Table 1; Table 2).

\section{Circulating Hemocytes}

In the Mating Status model, we found a nonsignificant trend for mated females to have lower numbers of circulating hemocytes than virgin females (Table 1; Figure 2). Female genotype strongly influenced the numbers of circulating hemocytes in the Mating Status model

(Table 1; Female Genotype: mean [lower, upper bounds of 95\% confidence interval] = E: 18533 [14168, 24243], F: 15624 [11992, 20355], I: 9138.47 [6984.26, 11957]). There was no significant effect of body size on circulating hemocytes (Table 1; Table 2). There was a significant genotype-by-genotype interaction on the number of circulating hemocytes in mated females in the GxG model (Table 2, Figure 2). 


\section{Proportions of Individuals with Microaggregations}

Mating status had a significant effect on the presence of microaggregations; mated females were significantly more likely to exhibit microaggregations than virgin females (Table 1; Figure 3). However, female genotype did not influence the presence of microaggregations (Table 1). In the GxG model, we found a nearly significant genotype-by-genotype interaction on the incidence of microaggregations (Table 2; Figure 3). Male genotype significantly affected the incidence of microaggregations in mated females; females mated to male of genotype $\mathrm{E}$ were more likely to have microaggregations than the females mated with males from other genotypes (Table 2). However, female genotype did not have a significant effect on the incidence of microaggregations (Table 2). Body size did not significantly influence the incidence of microaggregations (Table 1; Table 2).

\section{Discussion}

Our results show that male genotype interacts with female genotype to alter female cellular immunity post-mating in decorated crickets, G. sigillatus. Specifically, the number of circulating hemocytes in mated females was contingent on an interaction between her genotype and that of her mate. In addition to this component of cellular immunity, we found a trend for a genotype-by-genotype effect on the incidence of microaggregations. These male-by-female genotype interactions are consistent with effects of seminal proteins on female physiology that are expected to arise as a result of the coevolution of male and female genotypes driven by sexual conflict (Goenaga, Yamane, Rönn, \& Arnqvist, 2015; Haerty et al., 2007; Rice \& Holland, 1997). Ejaculates of males of different genotypes have divergent effects on female immunity, and similarly, female genotypes differ in their susceptibility. Male-by-female 
genotype interactions are known to influence a variety of post-mating reproductive processes in the sexes (Clark, Begun, \& Prout, 1999; Nilsson, Fricke, \& Arnqvist, 2003; Reinhart, Carney, Clark, \& Fiumera, 2014), but only one other study hints at the effect of a genotype-by-genotype interaction on female insect immunity post-mating. A recent study in Drosophila showed that the effects of mating on female immune gene expression depends on the interaction between the genotype of a female and that of her mate (Delbare, Chow, Wolfner, \& Clark, 2017). The gene expression profiles of females mated to males from their own local population differed from those mated to males from other locations, suggesting that females may be more susceptible to the effects of seminal proteins of males belonging to novel genotypes, a result that also aligns with a history of sexually antagonistic coevolution within populations (Delbare, Chow, Wolfner, \& Clark, 2017).

Mating per se had an influence on the incidence of microaggregations, as hemolymph of mated females was more likely to contain microaggregations than that of virgin females. This result is consistent with many previous studies reporting an effect of mating on female insect immunity (Delbare, Chow, Wolfner, \& Clark, 2017; Lawniczak et al., 2007; Oku, Price, \& Wedell, 2019; Schwenke, Lazzaro, \& Wolfner, 2016). In our study, we also found that female genotype strongly influences different components of female humoral and cellular immunity. Phenoloxidase activity of mated females was contingent on female genotype, but unlike female cellular immunity, there was no evidence of a male-by-female genotype interaction. The number of circulating hemocytes was also influenced by female genotype. These results align with the results of earlier studies showing that female G. sigillatus from different inbred lines exhibit differences in phenoloxidase activity and melanization of an implant (Gershman et al., 2010a), among other notable differences in life-history traits (Archer et al., 2012). 
One obvious candidate for the effect of mating and the male-by-female genotype interaction on female immunity documented here is seminal proteins or other compounds contained in the ejaculate and conversely the female receptors and responses to these. These are known to orchestrate a cascade of reproductive physiological effects in females of other insect taxa (Perry, Siro, \& Wigby, 2013). The effects of seminal proteins on female physiology postmating have been investigated most extensively in Drosophila (Avila et al., 2010; Ravi Ram \& Wolfner, 2007; Wolfner, 1997). For example, sex peptide, a well characterized accessory gland protein transferred to females in the male ejaculate of Drosophila, initially was considered to be mutually beneficial to both male and female fitness because it increased egg production of mated females (Wigby \& Chapman, 2005). However, sex peptide is also known to impose costs on females, such as decreased survival and, ultimately, decreased fitness (Chapman et al., 2003b; Wigby \& Chapman, 2005). Sex peptide's suite of effects include changes in female immunity (Peng, Zipperlen, \& Kubli, 2005; Domanitskaya, Liu, Chen, \& Kubli, 2007). Although the effect of mating and the male-by-female genotype interaction on female immunity in G. sigillatus could be a direct effect of seminal proteins transferred by males, they could also represent an indirect side effect. For example, Chapman et al. (1995) concluded that the decreased survival of mated female Drosophila could be a side effect of the accessory gland proteins that are responsible for other mating-induced changes in female physiology and behavior.

Other compounds transferred in the ejaculate could be contributing to the effect of mating on female immunity observed here. For example, in the field cricket, Gryllus texensis, prostaglandin, a well characterized reproductive eicosanoid in insects, is transferred to females via the male ejaculate (Worthington, Jurenka, \& Kelly, 2015). Prostaglandin and other eicosanoids are known to play an important role in insect immunity, including hemocyte 
activation, migration, and microaggregation (Miller, Nguyen, \& Stanley-Samuelson, 1994;

Stanley \& Kim, 2014). Worthington and Kelly (2016) attributed the increased survival of mated female G. texensis challenged with an experimental infection of Serratia marcescens compared with females experiencing courtship only, to the immunity-enhancing effects of prostaglandin transferred in the ejaculate. Such an effect could also explain the positive effect of mating on the incidence of microaggregations observed in the mated female crickets in our study. In contrast to seminal proteins, molecules such as eicosanoids are less likely to vary qualitatively across genotypes, with male lines instead differing quantitively in their production and female lines differing in their receipt and processing. Therefore, such molecules would not explain the observed genotype-by-genotype effects.

In addition to any effects mediated by compounds contained in male ejaculates, female decorated crickets may experience an alteration in immunity after mating due to an immune response to sperm as a foreign antigen. Sperm can elicit an immune response in female insects because they are recognized as non-self by the female immune system (Lawniczak et al., 2007; McGraw, Gibson, Clark, \& Wolfner, 2004). The increased disease resistance that has been observed in female crickets could be due, at least in part, to the activation of the female immune system triggered by sperm (McGraw, Gibson, Clark, \& Wolfner, 2004; Worthington \& Kelly, 2016). In support of this possibility, female G. texensis that were mated with unmanipulated males (i.e., males with ejaculates containing accessory fluids and testes-derived components) had higher survival after bacterial infection than females that experienced courtship, copulation without spermatophore transfer, or received accessory gland fluids from castrated males (Worthington \& Kelly, 2016). If the response to sperm as non-self is dependent on the 
combinatorial effect of the male and female genotypes, this has the potential to result in a malefemale genotype interaction determining female post-mating immunity.

It is possible that undetected sexually transmitted microbes altered female immunity after mating. Insects are host to a number of microbes that are facultatively or opportunistically sexually transmitted (Otti, 2015). It seems entirely possible that microbes present on the genitalia or in the reproductive organs of different male genotypes could lead to differences in female immune responses. However, this would likely result in an influence of male genotype on female immunity, and not an interaction between male and female genotypes.

In the decorated cricket study system used here, we cannot rule out the possibility that components of the nuptial gifts (i.e., spermatophylax) of males and orally ingested by females after mating contribute to the effect of mating and the male-by-female genotype interaction on female immunity reported here. Indeed, a recent proteomic investigation of the spermatophylax of G. sigillatus identified 30 different proteins, 18 of which are encoded by genes expressed in the male accessory glands and the functions of which have yet to be determined (Pauchet et al., 2015). Although these proteins are yet to be functionally characterized, two of these proteins have been suggested to function in protecting other active components from digestion and in physiological manipulation of the female, respectively (Pauchet et al., 2015). Comparable to seminal proteins, it is possible that specific accessory gland proteins in the spermatophylax have the potential to alter female physiology, including female cellular immunity, after the female has consumed the spermatophylax. Differences in male spermatophylax proteins and female responses to them across genotypes has the potential to underlie genotype-by-genotype effects. We also note that there was a significant effect of female genotype on the time spent feeding on the spermatophylax, but whether this contributed to the effect of female genotype on specific 
immune measures remains uncertain, because longer feeding times also leads to greater ejaculate transfer (Sakaluk, 1984). Disentangling the factors responsible for changes in female immunity, included the individual effects of seminal and spermatophylax proteins represents an interesting direction of future study in this system.

Regardless of the underlying proximate mechanism, the increase in female cellular immunity after mating is in line with previous work demonstrating an enhancement of female immunity following mating but counter to other studies demonstrating a corruption of female immunity (Lawniczak et al., 2007). The link between immunity and infection outcomes may not always be clear (Adamo, 2004), but the increase in female immunity may benefit both males and females directly or indirectly if this immune response protects the sperm, female, or her eggs from infection (Ravi Ram \& Wolfner, 2007). In addition to the effect of mating on the increased incidence of microaggregations in females documented here, mating is known to increase female immunity in other cricket species. In the ground cricket, Allonemobius socius, for example, multiply mated females exhibited higher phenoloxidase compared with virgin females (Fedorka, Zuk, \& Mousseau, 2004) and in the field cricket, Gryllus texensis, mated females exhibited higher survival rates than unmated females after experimental bacterial infection (Shoemaker, Parsons, \& Adamo, 2006; Worthington \& Kelly, 2016). The enhancement of female post-mating immunity has also been linked with a beneficial reduction of infection in other insects (Barribeau \& Schmid-Hempel, 2016).

In conclusion, we show that the cellular immunity of female decorated crickets is altered as a result of mating, as well as provide evidence for a male-female genotype-by-genotype interaction on female immunity. Our findings suggest that the outcome of mating on insect female immunity is not only dependent on female genotype, but also the genotype of her mate, 
resulting in differences in the form, magnitude, and direction of female immune response. Future studies are required to determine whether male ejaculates have evolved specifically to manipulate female immunity in G. sigillatus as an adaptation favored in the context of sexual conflict, or if levels of female immunity after mating are merely an incidental effect of other manipulations of female physiology or response to non-self, such as sperm received at copulation. 


\section{REFERENCES}

Adamo, S.A. (2004). Estimating disease resistance in insects: phenoloxidase and lysozyme-like activity and disease resistance in the cricket Gryllus texensis. Journal of Insect Physiology, 50, 209-216. https://doi.org/10.1016/j.jinsphys.2003.11.011

Alcock, J. (1994). Postinsemination associations between males and females in insects: The mate-guarding hypothesis. Annual Review of Entomology, 39, 1-21. Retrieved from: https://www.annualreviews.org/doi/pdf/10.1146/annurev.en.39.010194.000245

Archer, C.R., Zajitschek, F., Sakaluk, S.K., Royle, N.J., \& Hunt, J. (2012). Sexual selection affects the evolution of lifespan and ageing in the decorated cricket Gryllodes sigillatus. Evolution, 66, 3088-3100. https://doi.org/10.1111/j.1558-5646.2012.01673.x

Arnqvist, G. (1988). Mate guarding and sperm displacement in the water strider Gerris lateralis Schumm. (Heteroptera: Gerridae). Freshwater Biology, 19, 269-274. https://doi.org/10.1111/j.1365-2427.1988.tb00347.x

Arnqvist, G. \& Nilsson, T. (2000). The evolution of polyandry: Multiple mating and female fitness in insects. Animal Behaviour, 60, 145-164. https://doi.org/10.1006/anbe.2000.1446

Arnqvist, G. \& Rowe, L. (2002). Antagonistic coevolution between the sexes in a group of insects. Nature, 415, 787-789. DOI:10.1038/415787a

Avila, F.W., Sirot, L.K., Laflamme, B.A., Rubinstein, C.D., \& Wolfner, M.F. (2010). Insect seminal fluid proteins: Identification and function. Annual Review of Entomology, 56, 2140. https://doi.org/10.1146/annurev-ento-120709-144823 
Baer, B., Morgan, E.D., \& Schmid-Hempel, P. (2001). A nonspecific fatty acid within the bumblebee mating plug prevents females from remating. Proceedings of the National Academy of Sciences of United States of America, 98, 3926-3928.

https://doi.org/10.1073/pnas.061027998

Barribeau, S.M. \& Schmid-Hempel, P. (2017). Sexual healing: mating induces a protective immune response in bumblebees. Journal of Evolutionary Biology, 30, 202-209. https://doi.org/10.1111/jeb.12964

Burpee, D.M. \& Sakaluk, S.K. (1993). Repeated matings offset costs of reproduction in female crickets. Evolutionary Ecology, 7, 240-250. https://doi.org/10.1007/BF01237742

Chapman, T., Liddle, L.F., Kalb, J.M., Wolfner, M.F., \& Partridge, L. (1995). Cost of mating in Drosophila melanogaster females is mediated by male accessory gland products. Nature, 373, 241-244. DOI: 10.1038/373241a0

Chapman, T., Arnqvist, G., Bangham, J., \& Rowe, L. (2003a). Sexual conflict. Trends in Ecology \& Evolution, 18, 41-47. https://doi.org/10.1016/S0169-5347(02)00004-6

Chapman, T., Bangham, J., Vinti, G., Seifried, B., Lung, O., Wolfner, M.F., Smith, H.K., \& Partridge, L. (2003b). The sex peptide of Drosophila melanogaster: Female post-mating responses analyzed by using RNA interference. Proceedings of the National Academy of Sciences of United States of America, 100, 9923-9928. https://doi.org/10.1073/pnas.1631635100

Clark, A.G., Begun, D.J., \& Prout, T. (1999). Female x male interactions in Drosophila sperm competition. Science, 283, 217-220. DOI: 10.1126/science.283.5399.217 
Cordero, A. (1990). The adaptive significance of the prolonged copulations of the damselfly, Ischnura graellsii (Odonata: Coenagrionidae). Animal Behavior, 40, 43-48. https://doi.org/10.1016/S0003-3472(05)80664-5

Cordero, A. (1999). Forced copulations and female contact guarding at a high male density in a calopterygid damselfly. Journal of Insect Behavior, 12, 27-37. Retrieved from: https://link.springer.com/content/pdf/10.1023/A:1020972913683.pdf

Delbare, S.Y.N., Chow, C.Y., Wolfner, M.F., \& Clark, A.G. (2017). Roles of female and male genotype in post-mating responses in Drosophila melanogaster. Journal of Heredity, 4, 740-753. https://doi.org/10.1093/jhered/esx081

Dickinson, J.L. \& Rutowski, R.L. (1989). The function of the mating plug in the chalcedon checkerspot butterfly. Animal Behavior, 38, 154-162. https://doi.org/10.1016/S00033472(89)80074-0

Domanitskaya, E.V., Liu, H., Chen, S., \& Kubli, E., (2007). The hydroxyproline motif of male sex peptide elicits the innate immune response in Drosophila females. The FEBS Journal, 274, 5659-5668. https://doi.org/10.1111/febs.15131

Dougherty, L.R., van Lieshout, E., McNamara, K.B., Moschilla, J.A., Arnqvist, G., \& Simmons, L.W. (2017). Sexual conflict and correlated evolution between male persistence and female resistance traits in the seed beetle Callosobruchus maculatus. Proceedings of the Royal Society B: Biological Sciences, 284, 20170132. https://doi.org/10.1098/rspb.2017.0132

Duffield, K.R., Hampton, K.J., Houslay, T.M., Hunt, J., Rapkin, J., Sakaluk, S.K., \& Sadd, B.M. (2018). Age-dependent variation in the terminal investment threshold in male crickets. Evolution, 72, 578-589. https://doi.org/10.1111/evo.13443 
Duffield, K.R., Hampton, K.J., Houslay, T.M., Hunt, J., Sadd, B.M., \& Sakaluk, S.K. (2019). Inbreeding alters context-dependent reproductive effort and immunity in male crickets. Journal of Evolutionary Biology, 32, 731-741. https://doi.org/10.1111/jeb.13478

Eggert, A.K., Reinhardt, K., \& Sakaluk., S.K. (2003). Linear models for assessing mechanisms of sperm competition: the trouble with transformations. Evolution, 57, 173-176. https://doi.org/10.1111/j.0014-3820.2003.tb00227.x

Fedorka, K.M., Zuk, M., \& Mousseau, T.A. (2004). Immune suppression and the cost of reproduction in the ground cricket, Allonemobius socius. Evolution, 58, 2478-2485. https://doi.org/10.1111/j.0014-3820.2004.tb00877.x

Gershman, S.N., Barnett, C.A., Pettinger, A.M., Weddle, C.B., Hunt, J., \& Sakaluk, S.K. (2010a). Inbred decorated crickets exhibit higher measures of macroparasitic immunity than outbred individuals. Heredity, 105, 282-289. https://doi.org/10.1038/hdy.2010.1

Gershman, S.N., Barnett, C.A., Pettinger, A.M., Weddle, C.B., Hunt, J., \& Sakaluk, S.K. (2010b). Give 'til it hurts: trade-offs between immunity and male reproductive effort in the decorated cricket, Gryllodes sigillatus. Journal of Evolutionary Biology, 23, 829-839. https://doi.org/10.1111/j.1420-9101.2010.01951.x

Gershman, S.N., Mitchell, C., Sakaluk, S.K., \& Hunt, J. (2012). Biting off more than you can chew: sexual selection on the free amino acid composition of the spermatophylax in decorated crickets. Proceedings of the Royal Society B: Biological Sciences, 279, 25312538. https://doi.org/10.1098/rspb.2011.2592

Gershman, S.N., Hunt, J., \& Sakaluk, S.K. (2013). Food fight: sexual conflict over free amino acids in the nuptial gifts of male decorated crickets. Journal of Evolutionary Biology, 26, 693-704. https://doi.org/10.1111/jeb.12078 
Gillespie, J.P., Kanost, M.R., \& Trenczek, T. (1997). Biological mediators of insect immunity. Annual Review of Entomology, 42, 611-654. https://doi.org/10.1146/annurev.ento.42.1.611

Gillott, C. (2003). Male accessory gland secretions: Modulators of female reproductive physiology and behavior. Annual Review of Entomology, 48, 163-184. https://doi.org/10.1146/annurev.ento.48.091801.112657

Goenaga, J., Yamane, T., Rönn, J., \& Arnqvist, G. (2015). Within-species divergence in the seminal fluid proteome and its effect on male and female reproduction in a beetle. $B M C$ Evolutionary Biology, 15, 266. https://doi.org/10.1186/s12862-015-0547-2

González-Santoyo, I. \& Córdoba-Aguilar, A. (2012). Phenoloxidase: a key component of the insect immune system. Entomologica Experimentalis et Applicata, 142, 1-16. https://doi.org/10.1111/j.1570-7458.2011.01187.x

Haerty, W., Jagadeeshan, S., Kulathinal, R.J., Wong, A., Ravi Ram, K., Sirot, L.K., Levesque, L., Artieri, C.G., Wolfner, M.F., Civetta, A., \& Singh, R.S. (2007). Evolution in the fast lane: Rapidly evolving sex-related genes in Drosophila. Genetics, 177, 1321-1335. https://doi.org/10.1534/genetics.107.078865

Ivy, T.M. \& Sakaluk, S.K. (2005). Polyandry promotes enhanced offspring survival in decorated crickets. Evolution, 59, 152-159. https://doi.org/10.1111/j.0014-3820.2005.tb00902.x

Ivy, T.M., Weddle, C.B., \& Sakaluk, S.K. (2005). Females use self-referent cues to avoid mating with previous mates. Proceedings of the Royal Society B: Biological Sciences, 272, 24752478. https://doi.org/10.1098/rspb.2005.3222

Kerr, A.M., Gershman, S.N., \& Sakaluk, S.K. (2010). Experimentally induced spermatophore production and immune responses reveal a trade-off in crickets. Behavioral Ecology, 21, 647-654. https://doi.org/10.1093/beheco/arq035 
Klowden, M.J. (1999). The check is in the male: Male mosquitoes affect female physiology and behavior. Joumal of the American Mosquito Control Association, 15, 213-220. Retrieved from: https://www.biodiversitylibrary.org/content/part/JAMCA/JAMCA_V15_N2_P213220.pdf

Lavine, M.D. \& Strand, M.R. (2002). Insect hemocytes and their role in immunity. Insect Biochemistry and Molecular Biology, 32, 1295-1309. https://doi.org/10.1016/S09651748(02)00092-9

Lawniczak, M.K.N., Barnes, A.I., Linklater, J.R., Boone, J.M., Wigby, S., \& Chapman, T. (2007). Mating and immunity in invertebrates. Trends in Ecology and Evolution, 22, 48-55. https://doi.org/10.1016/j.tree.2006.09.012

Lung, O. \& Wolfner, M.F. (2001). Identification and characterization of the major Drosophila melanogaster mating plug protein. Insect Biochemistry and Molecular Biology, 31, 543551. https://doi.org/10.1016/S0965-1748(00)00154-5

McGraw, L.A., Gibson, G., Clark, A.G., \& Wolfner, M.F. (2004). Genes regulated by mating, sperm, or seminal proteins in mated female Drosophila melanogaster. Current Biology, 14, 1509-1514. https://doi.org/10.1016/j.cub.2004.08.028

Miller, J.S., Nguyen, T., \& Stanley-Samuelson, D.W. (1994). Eicosanoids mediate insect nodulation responses to bacterial infections. Proceedings of the National Academy of Sciences of United States of America, 91, 12418-12422. https://doi.org/10.1073/pnas.91.26.12418

Nappi, A.J. \& Vass, E. (1993). Melanogenesis and the generation of cytotoxic molecules during insect cellular immune reactions. Pigment Cell Research, 6, 117-126. https://doi.org/10.1111/j.1600-0749.1993.tb00590.x 
Nilsson, T., Fricke, C., \& Arnqvist, G. (2003). The effects of male and female genotype on variance in male fertilization success in the red flour beetle (Tribolium castaneum). Behavioral Ecology and Sociobiology, 53, 227-233. https://doi.org/10.1007/s00265-0020565-0

Oku, K., Price, T.A.R., \& Wedell, N. (2019). Does mating negatively affect female immune defences in insects? Animal Biology, 69, 117-136. https://doi.org/10.1163/1570756320191082

Otti, O., (2015). Genitalia-associated microbes in insects. Insect Science, 22, 325-339. https://doi.org/10.1111/1744-7917.12183

Parker, G.A. \& Birkhead, T.R. (2013). Polyandry: the history of a revolution. Philosophical Transactions of the Royal Society B: Biological Sciences, 368, 1-13. https://doi.org/10.1098/rstb.2012.0335

Pauchet, Y., Wielsch, N., Wilkinson, P.A., Sakaluk, S.K., Svatoš, A., ffrench-Constant, R.H., Hunt, J., \& Heckel, D.G. (2015). What's in the gift? Towards a molecular dissection of nuptial feeding in a cricket. PLoS One, 10, e0140191. https://doi.org/10.1371/journal.pone.0140191 .

Peng, J., Zipperlen, P., \& Kubli, E. (2005). Drosophila sex-peptide stimulates female innate immune system after mating via the Toll and Imd pathways. Current Biology, 15, 16901694. https://doi.org/10.1016/j.cub.2005.08.048

Perry, J.C., Siro, L., and Wigby, S. (2013). The seminal symphony: how to compose an ejaculate. Trends in Ecology and Evolution, 28, 414-422. https://doi.org/10.1016/j.tree.2013.03.005 
Ravi Ram, K. \& Wolfner, M.F. (2007). Seminal influences: Drosophila acps and the molecular interplay between males and females during reproduction. Integrative \& Comparative. Biology, 47, 427-445. https://doi.org/10.1093/icb/icm046

Reinhart, M., Carney, T., Clark, A.G., \& Fiumera, A.C. (2014). Characterizing male-female interactions using natural genetic variation in Drosophila melanogaster. Journal of Heredity, 2015, 67-79. https://doi.org/10.1093/jhered/esu076

Rice, W.R. \& Holland, B. (1997). The enemies within: intergenomic conflict, interlocus contest evolution (ICE), and the intraspecific red queen. Behavioral Ecology and Sociobiology, 41, 1-10. https://doi.org/10.1007/s002650050357

Rolff, J. \& Siva-Jothy, M.T. (2002). Copulation corrupts immunity: a mechanism for a cost of mating in insects. Proceedings of the National Academy of Sciences of United States of America,: 9916-9918. https://doi.org/10.1073/pnas.152271999

Rowe, L. \& Arnqvist, G. (2002). Sexually antagonistic coevolution in a mating system: cominbing experimental and comparative approaches to address evolutionary processes. Evolution, 56, 754-767. https://doi.org/10.1111/j.0014-3820.2002.tb01386.x

Sakaluk, S.K. (1984). Male crickets feed females to ensure complete sperm transfer. Science, 223, 609-610. DOI: 10.1126/science.223.4636.609

Sakaluk, S.K. (1986). Sperm competition and the evolution of nuptial feeding behavior in the cricket, Gryllodes supplicans (Walker). Evolution, 40, 584-593. https://doi.org/10.1111/j.1558-5646.1986.tb00509.x

Sakaluk, S.K. (1987). Reproductive behaviour of the decorated cricket, Gryllodes supplicans (Orthoptera: Gryllidae): calling schedules, spatial distribution, and mating. Behaviour, 100, 202-225. Retrieved from www.jstor.org/stable/4534582 
Sakaluk, S.K. (1991). Post-copulatory mate guarding in decorated crickets. Animal Behavior, 41, 207-216. https://doi.org/10.1016/S0003-3472(05)80472-5

Sakaluk, S.K. (2000). Sensory exploitation as an evolutionary origin to nuptial food gifts in insects. Proceedings of the Royal Society B: Biological Sciences, 267, 339-343. https://doi.org/10.1098/rspb.2000.1006

Sakaluk, S.K., Avery, R.L., \& Weddle, C.B. (2006). Cryptic sexual conflict in gift-giving insects: Chasing the chase-away. The American Naturalist, 167, 94-104. https://doi.org/10.1086/498279

Sakaluk, S.K., Duffield, K.R., Rapkin, J., Sadd, B.M, \& Hunt., J. (2019). The troublesome gift: the spermatophylax as a purveyor of sexual conflict and coercion in crickets. Advances in the Study of Behavior, 51, 1-30. https://doi.org/10.1016/bs.asb.2018.12.001

Sakaluk, S.K. \& Eggert, A.K. (1996). Female control of sperm transfer and intraspecific variation in sperm precedence: antecedents to the evolution of a courtship food gift. Evolution, 50, 694-703. https://doi.org/10.1111/j.1558-5646.1996.tb03879.x

Sakaluk, S.K., Schaus, J.M., Eggert, A.K., Snedden, W.A., \& Brady, P.L. (2002). Polyandry and fitness of offspring reared under varying nutritional stress in decorated crickets. Evolution, 56, 1999-2007. https://doi.org/10.1111/j.0014-3820.2002.tb00126.x

Schneider, C.A., Rasband, W.S., \& Eliceiri, K.W. (2012). NIH Image to ImageJ: 25 years of image analysis. Nature Methods, 9, 671-675. https://doi.org/10.1038/nmeth.2089

Schneider, P.M. (1985). Purification and properties of three lysozymes from hemolymph of the cricket, Gryllus bimaculatus (De Geer). Insect Biochemistry, 15, 463-470. https://doi.org/10.1016/0020-1790(85)90058-7 
Schwenke, R.A., Lazzaro, B.P., \& Wolfner, M.F. (2016). Reproduction-immunity trade-offs in insects. Annual Review of Entomology, 61, 239-256. https://doi.org/10.1146/annurev-ento010715-023924

Sherman, K.J. (1983). The adaptive significance of postcopulatory mate guarding in a dragonfly, Pachydiplax longipennis. Animal Behavior, 31, 1107-1115. https://doi.org/10.1016/S00033472(83)80018-9

Shoemaker, K.L., Parsons, N.M., \& Adamo, S.A. (2006). Mating enhances parasite resistance in the cricket Gryllus texensis. Animal Behavior, 71, 371-380. https://doi.org/10.1016/j.anbehav.2005.05.007

Short, S.M. \& Lazzaro, B.P. (2010). Female and male genetic contributions to post-mating immune defence in female Drosophila melanogaster. Proceedings of the Royal Society B: Biological Sciences, 277, 3649-3657. https://doi.org/10.1098/rspb.2010.0937

Soderhall, K. \& Cerenius, L. (1998). Role of the prophenoloxidase-activating system in invertebrate immunity. Current Opinion in Immunology, 10, 23-28. https://doi.org/10.1016/S0952-7915(98)80026-5

Stanley, D. \& Kim, Y. (2014). Eicosanoid signaling in insects: From discovery to plant protection. Critical Reviews in Plant Sciences, 33, 20-63. https://doi.org/10.1080/07352689.2014.847631

Sugumaran, M., Nellaiappan, K., \& Valivittan, K. (2000). A new mechanism for the control of phenoloxidase activity: Inhibition and complex formation with quinone isomerase. Archives of Biochemistry and Biophysics, 379, 252-260. https://doi.org/10.1006/abbi.2000.1884 
Warwick, S., Vahed, K., Raubenheimer, D., \& Simpson, S.J. (2009). Free amino acids as phagostimulants in cricket nuptial gifts: support for the "candymaker" hypothesis. Biology Letters, 5, 194-196. https://doi.org/10.1098/rsbl.2008.0731

Wigby, S. \& Chapman, T. (2005). Sex peptide causes mating costs in female Drosophila melanogaster. Current Biology, 15, 316-321. https://doi.org/10.1016/j.cub.2005.01.051

Wolfner, M.F. (1997). Tokens of love: Functions and regulation of Drosophila male accessory gland products. Insect Biochemistry and Molecular Biology, 27, 179-192. https://doi.org/10.1016/S0965-1748(96)00084-7

Worthington, A.M., Jurenka, R.A., \& Kelly, C.D. (2015). Mating for male-derived prostaglandin: a functional explanation for the increased fecundity of mated female crickets? Journal of Experimental Biology, 218, 2720-2727. DOI: 10.1242/jeb.121327

Worthington, A.M. \& Kelly, C.D. (2016). Females gain survival benefits from immune-boosting ejaculates. Evolution, 70, 928-933. https://doi.org/10.1111/evo.12890

Yi, H.Y., Chowdhury, M., Huang, Y.D., \& Yu, X.Q. (2014). Insect antimicrobial peptides and their applications. Applied Microbiology and Biotechnology, 98, 5807-5822. https://doi.org/10.1007/s00253-014-5792-6

Zhong, W., Priest, N.K., McClure, C.D., Evans, C.R., Mlynski, D.T., Immonen, E., Ritchie, M.G., \& Priest, N.K. (2013). Immune anticipation of mating in Drosophila: turandot m promotes immunity against sexually transmitted fungal infections. Proceedings of the Royal Society B: Biological Sciences, 280, 1-9. https://doi.org/10.1098/rspb.2013.2018 


\section{APPENDIX A: TABLES AND FIGURES}

TABLE A-1. Model terms and statistics for Mating Status models of female decorated cricket immune measures.

\begin{tabular}{lccc}
\hline Response measured & $D F$ & $F$ & $P$ \\
\hline Antibacterial activity & 1 & & \\
Body size & 2 & 2.17 & $\mathbf{0 . 0 4 3 4}$ \\
Female genotype & 1 & 1.73 & $\mathbf{0 . 5 2 4 5}$ \\
Mating status & & & $\mathbf{0 . 1 4 7 3}$ \\
PO activity & 1 & 0.03 & 0.4981 \\
Body size & 2 & 2.15 & $\mathbf{0 . 1 2 0 5}$ \\
Female genotype & 1 & 1.26 & $\mathbf{0 . 2 6 3 5}$ \\
Mating status & & & \\
& & & 0.7449 \\
Hemocyte counts & 1 & 0.11 & $\mathbf{0 . 0 0 1 1}$ \\
Body size & 2 & 7.21 & $\mathbf{0 . 1 9 4 1}$ \\
Female genotype & 1 & 1.70 & \\
Mating status & & & 0.3935 \\
Microaggregations & & 0.73 & $\mathbf{0 . 3 7 8 8}$ \\
Body size & 1 & 0.98 & $\mathbf{0 . 0 1 2 0} *$ \\
Female genotype & 2 & 6.50 &
\end{tabular}

Bolded terms were retained in the final model. Asterisks represent significant effects $(\alpha=0.05)$. 
TABLE A-2. Model terms and statistics for GxG models of female decorated cricket immune measures.

\begin{tabular}{|c|c|c|c|}
\hline Response measured & $D F$ & $F$ & $P$ \\
\hline \multicolumn{4}{|l|}{ Antibacterial activity } \\
\hline Body size & 1 & 3.15 & 0.0778 \\
\hline Male genotype & 2 & 0.29 & 0.7822 \\
\hline Female genotype & 2 & 2.16 & 0.2516 \\
\hline $\begin{array}{l}\text { Male genotype*female } \\
\text { genotype }\end{array}$ & 4 & 0.21 & 0.8620 \\
\hline \multicolumn{4}{|l|}{$P O$ activity } \\
\hline Body size & 1 & 1.79 & 0.1832 \\
\hline Male genotype & 2 & 0.26 & 0.7730 \\
\hline Female genotype & 2 & 3.33 & $0.0379 *$ \\
\hline Male genotype*female & 4 & 0.82 & 0.5134 \\
\hline \multicolumn{4}{|l|}{ Hemocyte counts } \\
\hline Body size & 1 & 0.69 & 0.4078 \\
\hline Male genotype & 2 & 6.84 & $0.0014 *$ \\
\hline Female genotype & 2 & 11.07 & $<.0001 *$ \\
\hline $\begin{array}{l}\text { Male genotype*female } \\
\text { genotype }\end{array}$ & 4 & 2.74 & $0.0300 *$ \\
\hline \multicolumn{4}{|l|}{ Microaggregations } \\
\hline Body size & 1 & 0.13 & 0.7166 \\
\hline Male genotype & 2 & 3.70 & $0.0265 *$ \\
\hline Female genotype & 2 & 0.97 & 0.3812 \\
\hline $\begin{array}{l}\text { Male genotype*female } \\
\text { genotype }\end{array}$ & 4 & 2.37 & $\mathbf{0 . 0 5 3 8}$ \\
\hline
\end{tabular}

Bolded terms were retained in the final model. Asterisks represent significant effects $(\alpha=0.05)$. 


\begin{tabular}{|c|c|c|c|c|c|}
\hline & \multirow{2}{*}{ Virgin } & \multicolumn{3}{|c|}{ Mated (Male Genotype) } \\
\hline & & & E & $F$ & | \\
\hline \multirow{3}{*}{ 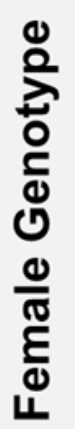 } & E & $E$ & $\begin{array}{c}E x E \\
22\end{array}$ & $\begin{array}{c}\text { ExF } \\
20\end{array}$ & $\begin{array}{c}\text { Exl } \\
21\end{array}$ \\
\hline & $\mathbf{F}$ & $\mathrm{F}$ & $\begin{array}{c}\text { FxE } \\
21\end{array}$ & $\begin{array}{c}F x F \\
22\end{array}$ & $\begin{array}{c}\mathrm{Fxl} \\
21\end{array}$ \\
\hline & I & I & $\begin{array}{c}\text { IxE } \\
21\end{array}$ & $\begin{array}{c}\text { IXF } \\
25\end{array}$ & $\begin{array}{l}|x| \\
21\end{array}$ \\
\hline
\end{tabular}

FIGURE A-1. Experimental design of females belonging to either mating treatment (Virgin, Mated) and female genotype by male genotype combinations nested within the mated treatment. For the analysis of the effect of mating per se on female immunity, only within genotype matings (italicized) were used. Numbers within cells represent sample sizes for GxG models of female decorated cricket immune measures. For the Mating Status models, the sample size for mated females are the sum of the within line matings (65), with the sample size for virgin females being 64 for antibacterial activity and 66 for the other two immune measures. 


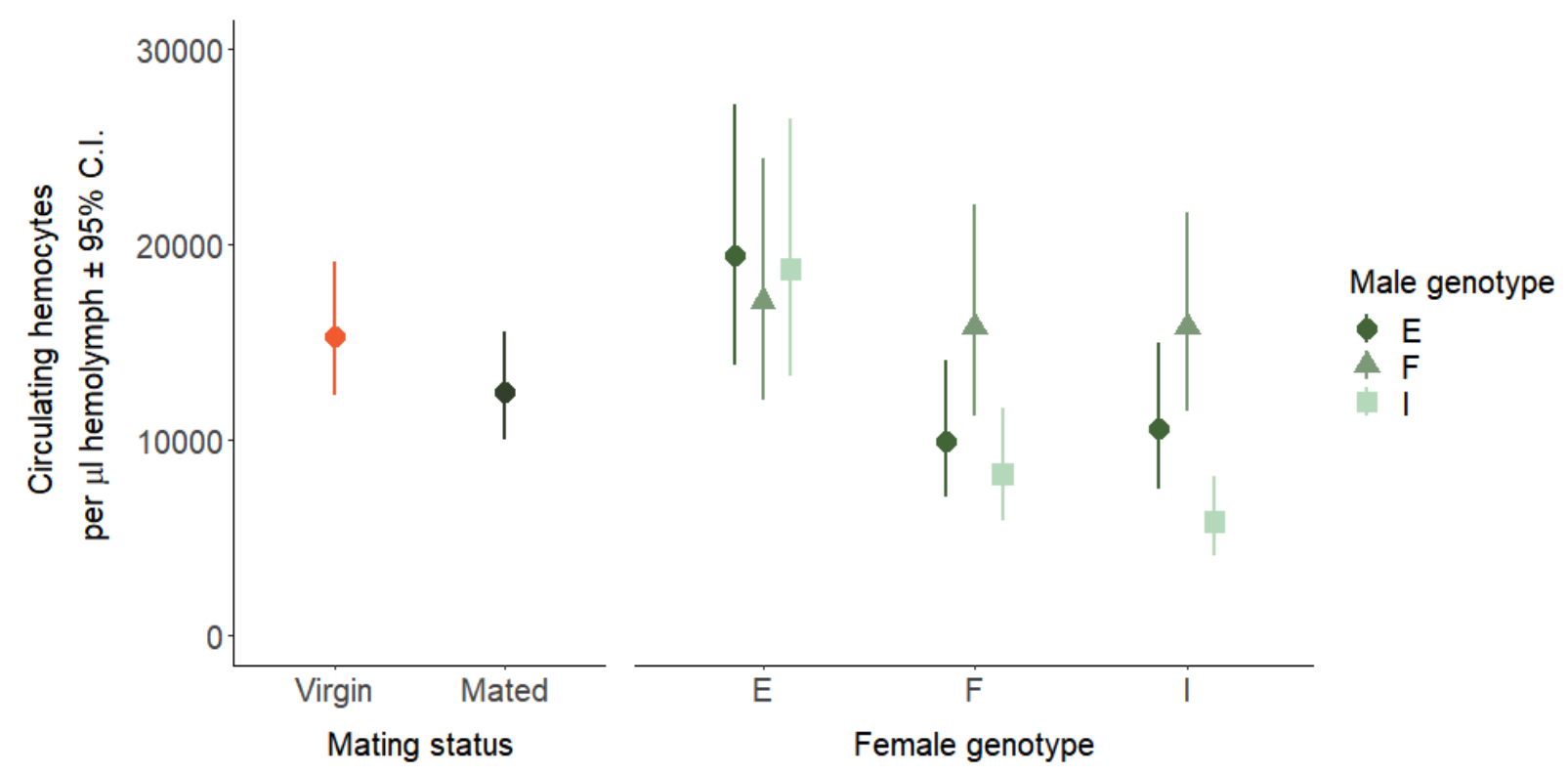

FIGURE A-2. Circulating hemocytes (least square means $\pm 95 \%$ confidence intervals) for mated and virgin female decorated crickets (left) and circulating hemocytes (least square means $\pm 95 \%$ confidence intervals) of females from three genotypic backgrounds (E, F, and I) mated to males with the same genotype or different genotype (E, F, and I; right). 


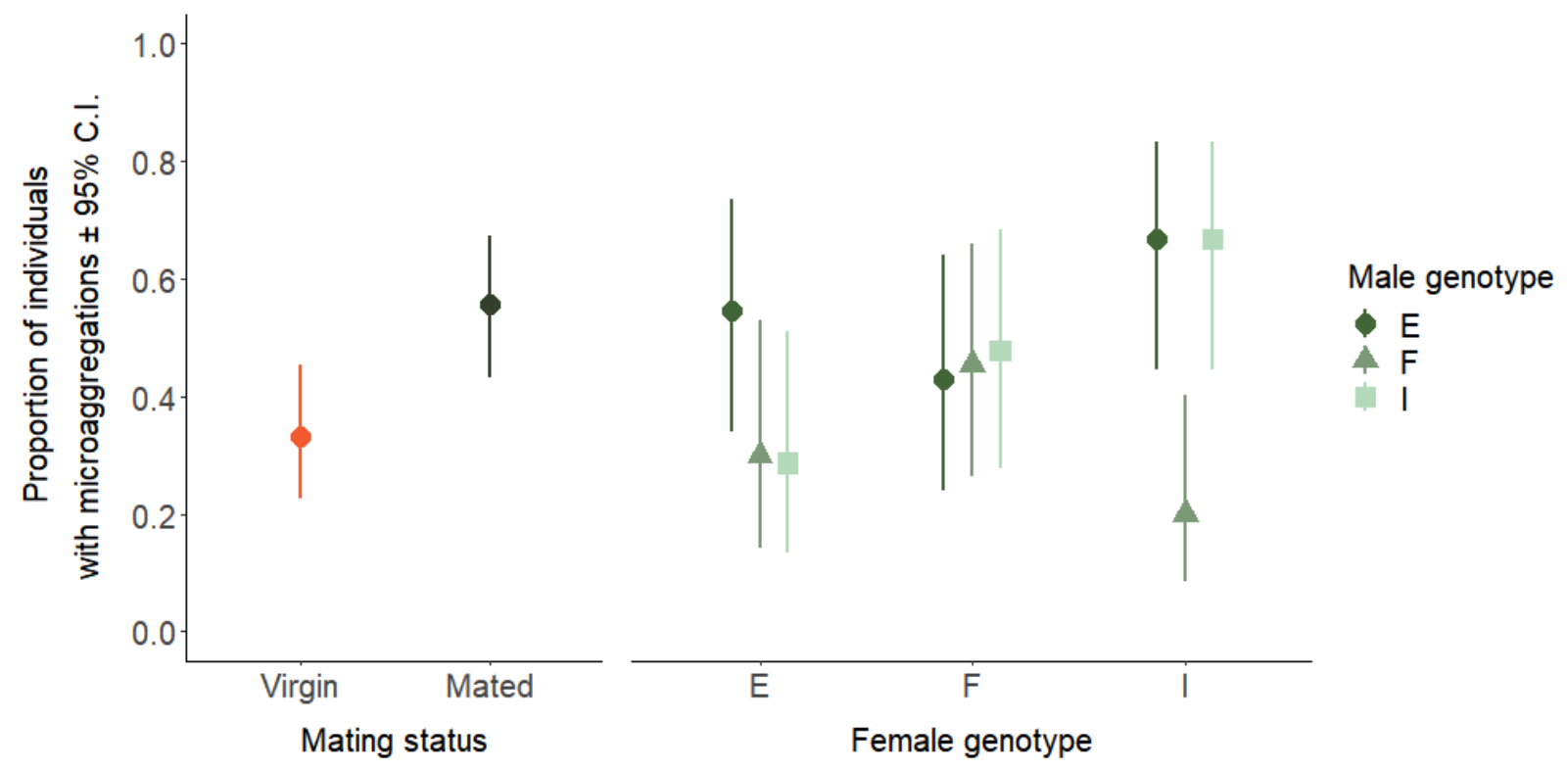

FIGURE A-3. Proportion of individuals with microaggregations present in the hemolymph (least square means $\pm 95 \%$ confidence intervals) for mated and virgin female decorated crickets (left) and proportion of females from three genotypic backgrounds (E, F, and I) with microaggregations present in the hemolymph (least square means $\pm 95 \%$ confidence intervals) after being mated to males with the same genetic background or different genetic background (E, F, and I; right). 